\title{
Análise do Índice de Anomalia de Chuva na região do extremo sul do Estado do Espírito Santo - ES
}

Analysis of the Rain Anomaly Index in the extreme south region of the State of Espírito Santo - ES Análisis del Índice de Anomalía de Iluvia en la extrema región sur del Estado de Espírito Santo - ES

Mayara Gabriela Lourenço Ferreira ORCID: https://orcid.org/0000-0002-6712-7896 Universidade Vale do Rio Verde, Brasil

E-mail: prof.mayara.lourenco@unincor.edu.br

Pablo Christian de Moro Silva

ORCID: https://orcid.org/0000-0002-6090-5106 Universidade Vale do Rio Verde, Brasil E-mail: prof.pablo.silva@unincor.edu.br

Fabiana Miranda Muniz

ORCID: https://orcid.org/0000-0002-9602-8934 Universidade Vale do Rio Verde, Brasil

E-mail: prof.fabiana.muniz@unincor.edu.br

Daniela Cristina Oliveira Anastácio

ORCID: https://orcid.org/0000-0003-1719-0640 Universidade Vale do Rio Verde, Brasil E-mail: danisvit@yahoo.com.br

José Pinto de Souza Neto

ORCID: https://orcid.org/0000-0001-9560-0823 Universidade Vale do Rio Verde, Brasil E-mail: jpsn70@outlook.com

Camila Faria de Almeida

ORCID: https://orcid.org/0000-0001-8289-5730 Universidade Vale do Rio Verde, Brasil E-mail: camilafar@gmail.com

Cinara Duplin Teixeira Pereira

ORCID: https://orcid.org/0000-0002-1601-8024 Universidade Vale do Rio Verde, Brasil

E-mail: cinaradupin@yahoo.com.br

Alisson Souza de Oliveira

ORCID: https://orcid.org/0000-0001-7885-9542 Universidade Vale do Rio Verde, Brasil E-mail: alissonso@hotmail.com

Rosângela Francisca de Paula Vitor Marques ORCID: https://orcid.org/0000-0001-6646-0809 Universidade Vale do Rio Verde, Brasil E-mail: reoflorestal@hotmail.com

Aurivan Soares de Freitas

ORCID: https://orcid.org/0000-0002-5322-3676 Universidade Vale do Rio Verde, Brasil E-mail: aurivan.soares@ hotmail.com

\section{Resumo}

Objetivou-se analisar a variabilidade temporal da precipitação pluviométrica na região das ottobacias dos Rios Itapemirim, Benevente e Itabapoana, sul do Espírito Santo, identificando assim os períodos secos e chuvosos por meio do Índice de Anomalia de Chuva. Foram selecionadas 10 estações pluviométricas pertencentes ao Instituto Nacional de Meteorologia (INMET), cuja a extensão da série foi de 1991 a 2020. Foram identificados em todas as estações períodos com anomalias positivas e negativas. Destaca-se as estações Vila Nova Maravilha, Ibitirama e Domingos Martins (DNOS) que foram classificadas como extremamente secas nos últimos anos. Em contra partida, as estações Ponta da Fruta, Fazenda Monte Alegre, Santa Cruz - Caparaó e Burarama apresentam uma condição hídrica mais favorável, de maneira geral, ocorre alternância entre anos com anomalias positivas e negativas. Foi identificado um possível "ponto de inflexão" em 2015, a partir do qual ocorre uma provável mudança no padrão de chuvas, quando se analise o Índice de Anomalia de Chuva médio. A precipitação média anual da região foi de 1466,4 mm, com 
variações entre 975,6 mm (estação Domingos Martins (DNOS), zona natural seca - sudeste da ottobacia do Rio Itapemirim) a 2010,1 mm (estação Vila Nova Maravilha, zona natural chuvosa - sudoeste da ottobacia Rio Benevente). Destaca-se a estação Burarama (região central da ottobacia do Rio Itapemirim) que apesar de localizada na zona natural seca, apresentou o segundo maior total precipitado (1659,6 mm). Os meses de fevereiro, abril, maio, junho, julho e setembro, apresentaram totais precipitados inferiores à média da região, cujo valor foi de $122,2 \mathrm{~mm}$.

Palavras-chave: IAC; Períodos secos e chuvosos; Precipitação pluviométrica.

\begin{abstract}
The objective was to analyze the temporal variability of the recovery capacity in the ottobasin region of the Itapemirim, Benevente and Itabapoana Rivers, south of Espírito Santo, thus identifying the dry and rainy periods through the Rain Anomaly Index. Ten rainfall stations belonging to the National Institute of Meteorology (INMET) were selected, whose series ranged from 1991 to 2020. Periods with positive and negative anomalies were identified in all stations. The Vila Nova Maravilha, Ibitirama and Domingos Martins (DNOS) stations stand out, which have been classified as extremely dry in recent years. On the other hand, the Ponta da Fruta, Fazenda Monte Alegre, Santa Cruz - Caparaó and Burarama stations have a more favorable water condition, in general, there is an alternation between years with positive and negative anomalies. A possible "inflection point" was identified in 2015, from which a likely change in rainfall pattern occurs, when analyzing the average Rain Anomaly Index. The average annual transition of the region was $1466.4 \mathrm{~mm}$, with variations between $975.6 \mathrm{~mm}$ (Domingos Martins station (DNOS), natural dry zone - southeast of the Itapemirim River ottobasin) to 2010,1 mm (Vila Nova Maravilha station, rainy natural zone - southwest of ottobacia Rio Benevente). The Burarama station (central region of the Itapemirim River ottobasin) stands out, which despite being located in the natural dry zone, had the second highest total precipitation $(1659.6 \mathrm{~mm})$. The months of February, April, May, June, July and September, total precipitation below the average for the region, whose value was $122.2 \mathrm{~mm}$.
\end{abstract}

Keywords: IAC; Dry and rainy periods; Rainfall.

\title{
Resumen
}

El objetivo fue analizar la variabilidad temporal de la capacidad de recuperación en la región ottobasin de los ríos Itapemirim, Benevente e Itabapoana, al sur de Espírito Santo, identificando así los períodos secos y lluviosos a través del Índice de Anomalías de Lluvia. Se seleccionaron diez estaciones pluviales pertenecientes al Instituto Nacional de Meteorología (INMET), cuya serie varió de 1991 a 2020. Se identificaron períodos con anomalías positivas y negativas en todas las estaciones. Destacan las estaciones de Vila Nova Maravilha, Ibitirama y Domingos Martins (DNOS), que han sido catalogadas como extremadamente secas en los últimos años. Por otro lado, las estaciones Ponta da Fruta, Fazenda Monte Alegre, Santa Cruz - Caparaó y Burarama tienen una condición de agua más favorable, en general, hay una alternancia entre años con anomalías positivas y negativas. En 2015 se identificó un posible "punto de inflexión", a partir del cual se produce un cambio probable en el patrón de lluvia, al analizar el índice de anomalía de lluvia promedio. La transición media anual de la región fue de 1466,4 mm, con variaciones entre 975,6 mm (estación Domingos Martins (DNOS), zona seca natural - sureste de la ottocuenca del río Itapemirim) a 2010,1 mm (estación Vila Nova Maravilha, zona natural lluviosa - al suroeste de ottobacia Rio Benevente). Destaca la estación de Burarama (región central de la ottobasin del río Itapemirim), que a pesar de estar ubicada en la zona natural seca, tuvo la segunda precipitación total más alta $(1659,6 \mathrm{~mm})$. Los meses de febrero, abril, mayo, junio, julio y septiembre presentaron precipitaciones totales por debajo del promedio de la región, cuyo valor fue de $122,2 \mathrm{~mm}$.

Palabras clave: IAC; Períodos secos y lluviosos; Lluvia.

\section{Introdução}

As significativas mudanças climáticas ocorridas em nível global têm desencadeado efeitos expressivamente impactantes nos mais variados processos hidrológicos regionais espalhados pelo mundo (Labat et al. 2004, Li et al. 2016). Os efeitos decorrentes de tais alterações climáticas acabam sendo potencializadas por interferência da ação humana, que diariamente incorre no uso irregular da terra e do manejo hídrico, além do próprio desmatamento, circunstâncias estas que provocam modificações graves no ciclo hidrológico local (Li et al. 2016).

Neste sentido, conforme preconiza Vilar (2020), prever e monitorar eventos climáticos e meteorológicos é de suma importância para o abastecimento de água, geração de energia elétrica e fomento de atividades agrícolas e pesqueiras, pois além de auxiliar no estudo de determinada região, possibilita averiguar os impactos que as alterações climáticas provocam e os seus possíveis causadores. A realização do monitoramento da ocorrência de chuvas severas e de secas extremas em uma 
determinada região é imprescindível, haja vista a necessidade de tornar viável a adaptação do ser humano em todos os aspectos necessários para sua existência.

Assim, considerando os paradigmas ora apresentados, faz-se necessário o conhecimento a respeito do comportamento pluviométrico de determinada região, a fim de que possa ser parametrizada a frequência de ocorrência de tempos secos e chuvosos, tendo em vista a grande interferência destes fenômenos na sobrevivência humana local consubstanciada pelas atividades de fomento à economia (Reis, et al. 2005).

Um dos grandes desafios é a compreensão do comportamento das precipitações sobre uma determinada área, da mesma maneira que o entendimento dos fatores que influenciam as chuvas é primordial para a tomada de decisões que envolvem essas áreas (Oliveira et al. 2020).

Dentre tantas variáveis climáticas, a precipitação pluviométrica pode acarretar impactos positivos ou negativos para sociedade local, visto que praticamente todas as atividades econômicas, especialmente a agrícola, sofrem a longo prazo por estas variações, contribuindo para o aumento significativo de eventos extremos de períodos de secas e chuvosos (Siqueira \& Nery, 2017).

Uma das possibilidades de se caracterizar a mutabilidade espaço tempo em uma determinada região de estudo, é através da utilização do cálculo do Índice de Anomalia de Chuva (IAC), desenvolvido por Rooy (1965), cuja função é considerar as austeridades positivas e negativas nas anomalias pluviométricas, auxiliando no monitoramento dos anos de seca e chuva excessiva e possibilitando a realização de comparações do regime pluviométrico a partir da série de dados históricos de chuva.

Maniçoba et al. (2017) salienta que o IAC ilustra muito bem o comportamento das precipitações em torno das normais climatológicas, apresentando-se como um bom indicador climático para se avaliar a variabilidade pluviométrica.

De acordo com Silva (2017), a utilização do cálculo do IAC para observar a variabilidade do comportamento climático de uma região apresenta-se como vantagem, uma vez que requer apenas dados de precipitação, o que facilita uma possível correção quando necessário. Assim, é possível desenvolver um sistema de acompanhamento dos predicados afetos aos períodos secos e úmidos de uma determinada região, com o intuito de se averiguar detalhadamente a climatologia desta e os possíveis impactos locais frutos da distribuição pluviométrica, consubstanciada na quantidade de precipitação local.

Neste sentido, o presente artigo pretende verificar o Índice de Anomalia de Chuvas (IAC) na região do extremo sul do Espírito Santo/ES, mais precisamente nas ottobacias do Rio Itapemirim, ITB Rio Benevente e Rio Itabapoana. A região encontra-se em um estado de importante desenvolvimento econômico e agrícola, fato este que intensifica e justifica a necessidade de se avaliar a distribuição pluviométrica local, haja vista a direta interferência dos regimes secos e chuvosos em seu desenvolvimento econômico.

\section{Metodologia}

\subsection{Caracterização, localização da área de estudo e base de dados}

A região em estudo localiza-se no extremo sul do estado do Espírito Santo, localizado no Sudeste do Brasil. Para o presente estudo foram consideradas a divisão das ottobacias nível 4 do estado, sendo as ottobacias do Rio Itapemirim, Rio Benevente e Rio Itabapoana.

O clima da ottobacia do Rio Itapemirim caracteriza-se, segundo a classificação climática de Köppen e Geiger (1928), pelos tipos $\mathrm{Cw}$, que corresponde ao clima subtropical de altitude, com inverno seco e verão ameno ( $\mathrm{Cwb}$ ), clima subtropical de inverno seco (com temperaturas inferiores a $18^{\circ} \mathrm{C}$ ) e verões quente, com temperaturas superiores a $22^{\circ} \mathrm{C}(\mathrm{Cwa})$, e $\mathrm{Aw}$, clima tropical, com estação chuvosa no verão (ALVARES et al. 2013). O clima da ottobacia do Rio Itapemerim, situada no extremo 
sul do estado do Espírito Santo, é do tipo Cwa, caracterizado pelo inverno seco e verão chuvoso. O clima varia à leste com Cwb - subtropical de altitude na serra do Caparaó e à oeste com clima Aw tropical de savana nas planícies litorâneas. Com relevo bastante movimentado, a área é constituída por uma paisagem fortemente ondulada e montanhosa (ESPÍRITO SANTO, 2018). O Clima da ottobacia da ITB Rio Benevente possui o clima da região é classificado como tropical úmido com estação seca de inverno (Aw). A precipitação média anual e a umidade relativa são iguais a $1.566 \mathrm{~mm}$ e 83\%, respectivamente, sendo a temperatura média anual igual a $22^{\circ} \mathrm{C}$ (LORENZON et al. 2015). E por último, segundo a classificação climática de Köppen e Geiger (1928), o clima da ottobacia do Rio Itabapoana é do tipo Cwa, caracterizado pela predominância de períodos quentes e inverno seco. A temperatura média anual é de $22^{\circ} \mathrm{C}$. A precipitação média anual é de $1200 \mathrm{~mm}$ e a umidade relativa média anual de 70\% (Espírito Santo, 2018).

A região sul do estado do Espírito Santo foi dividida em 10 zonas naturais. Na Tabela 1 são apresentadas as zonas naturais na região das estações pluviométricas utilizadas no estudo e suas classificações (Espírito Santo, 2018).

Tabela 1. Classificação da área de estudo de acordo com as Zonas Naturais do Estado do Espírito Santo.

\begin{tabular}{lcc}
\hline Código & Nome da Estação & Zonas naturais na região de estudo \\
\hline 2040005 & Iconha - Montante & Terras quentes, acidentadas e chuvosas \\
\hline 2040020 & Vila Nova Maravilha & Terras frias, acidentadas e chuvosas \\
\hline 2040022 & Ponta da Fruta & Terras quentes, planas e transição chuvosa/seca \\
\hline 2041000 & Atílio Vivacqua & Terras quentes, acidentadas e secas \\
\hline 2041001 & Guaçuí & Terras quentes, planas e transição chuvosa/seca \\
\hline 2041015 & Fazenda Monte Alegre & Terras de temperaturas amenas, acidentadas e chuvosas \\
\hline 2041017 & Santa Cruz - Caparaó & Terras frias, acidentadas e chuvosas \\
\hline 2041021 & Burarama & Terras quentes, acidentadas e secas \\
\hline 2041016 & Ibitirama & Terras frias, acidentadas e chuvosas \\
\hline 2040000 & Domingos Martins (DNOS) & Terras quentes, planas e secas \\
\hline
\end{tabular}

Fonte: Adaptado de Espírito Santo (1999).

Para a realização deste estudo, foram utilizados dados mensais de precipitação de 10 Estações Meteorológicas pertencentes à rede nacional de observações meteorológicas de superfície do Instituto Nacional de Meteorologia (INMET), distribuídas ao longo das ottobacias do Rio Itapemirim (estações 204000, 2041000, 2041015, 2041016, 2041017 e 2041021) Rio Itabapoana (estação 2041001), Rio Benevente (estações 2040005, 2040020 e 2040022), compreendendo os períodos entre 1991 e 2020, totalizando 30 anos de dados. A distribuição as estações utilizadas podem ser visualizadas na Figura 1. 
Research, Society and Development, v. 10, n. 11, e104101119278, 2021

(CC BY 4.0) | ISSN 2525-3409 | DOI: http://dx.doi.org/10.33448/rsd-v10i11.19278

Figura 1. Localização das ottobacias e estações pluviométricas no estado do Espírito Santo.

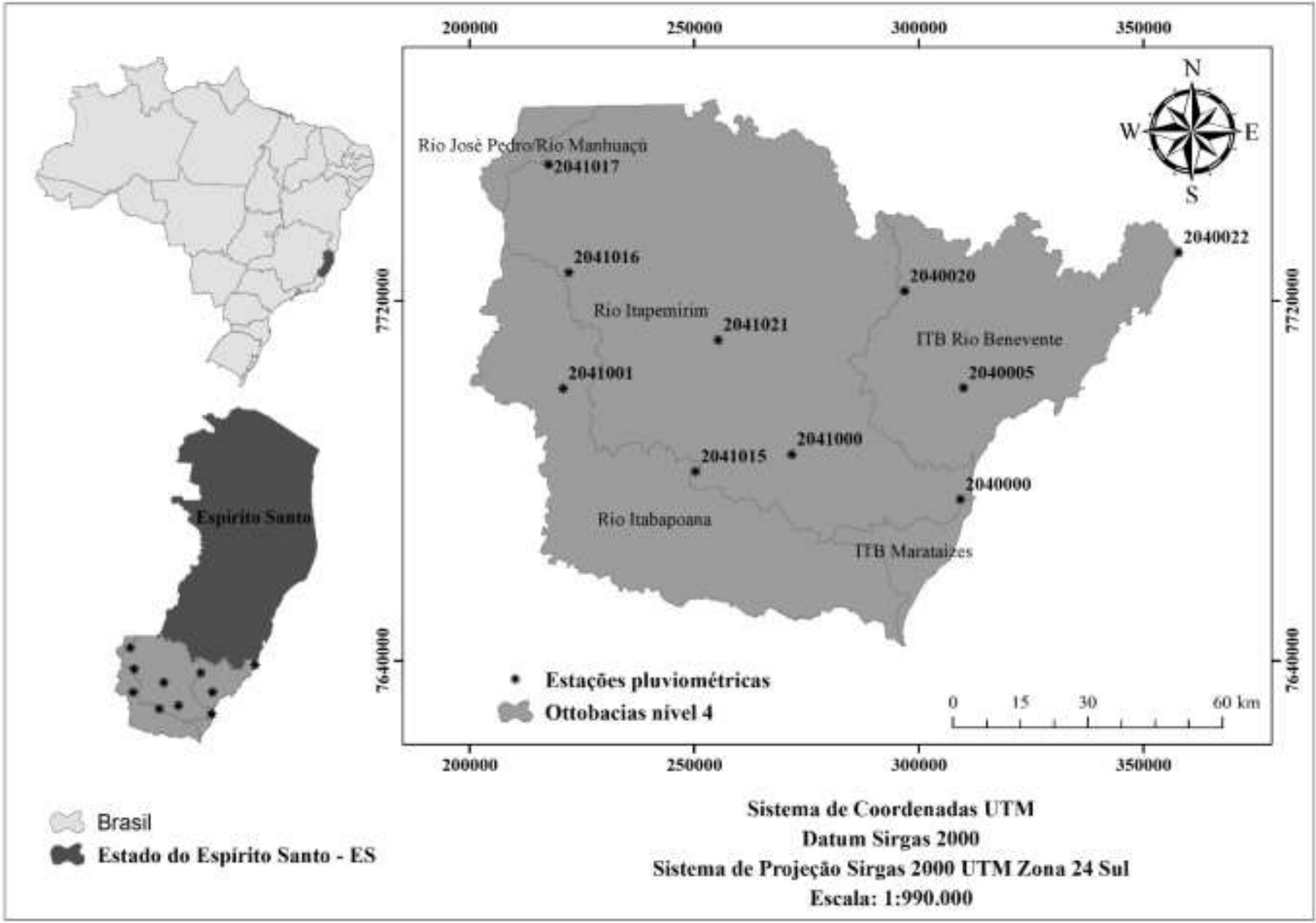

Fonte: Autores (2021).

A Tabela 2 apresenta as informações das 10 estações pluviométricas utilizadas, selecionadas em função da oferta de dados na região sul do Estado do Espírito Santo. 
Tabela 2. Estações pluviométricas utilizadas no estudo, incluindo a código de identificação, nome da estação / região, coordenadas, altitude e período de observação.

\begin{tabular}{ccccccc}
\hline Código & Nome da Estação & Município & $\begin{array}{c}\text { Latitude } \\
\text { (graus) }\end{array}$ & $\begin{array}{c}\text { Longitude } \\
\text { (graus) }\end{array}$ & $\begin{array}{c}\text { Altitude } \\
(\mathbf{m})\end{array}$ & $\begin{array}{c}\text { Período de } \\
\text { observação }\end{array}$ \\
\hline 2040005 & Iconha - Montante & Iconha & $-20,7836$ & $-40,8258$ & 25 & 1991 a 2020 \\
\hline 2040020 & Vila Nova Maravilha & $\begin{array}{c}\text { Alfredo } \\
\text { Chaves }\end{array}$ & $-20,5875$ & $-40,9492$ & 980 & 1991 a 2020 \\
\hline 2040022 & Ponta da Fruta & Vila Velha & $-20,5156$ & $-40,3636$ & 3 & 1991 a 2020 \\
\hline 2041000 & Atílio Vivácqua & $\begin{array}{c}\text { Atílio } \\
\text { Vivácqua }\end{array}$ & $-20,9128$ & $-41,1950$ & 76 & 1991 a 2020 \\
\hline 2041001 & Guaçuí & Guaçuí & $-20,7736$ & $-41,6817$ & 576 & 1991 a 2020 \\
\hline 2041015 & Fazenda Monte Alegre & Muqui & $-20,9447$ & $-41,4008$ & 450 & 1991 a 2020 \\
\hline 2041017 & Santa Cruz - Caparaó & Iúna & $-20,3228$ & $-41,7042$ & 920 & 1991 a 2020 \\
\hline 2041021 & Burarama & $\begin{array}{c}\text { Cachoeira do } \\
\text { Itapemirim }\end{array}$ & $-20,6806$ & $-41,3483$ & 180 & 1991 a 2020 \\
\hline 2041016 & Ibitirama & Alegre & $-20,5406$ & $-41,6656$ & 794 & 1991 a 2020 \\
\hline 2040000 & Domingos Martins & Domingos & $-20,3639$ & $-40,6617$ & 452 & 1991 a 2020 \\
\hline
\end{tabular}

Fonte: Autores (2021).

\subsection{Tratamento dos dados}

De posse dos dados pluviométricos foi realizada uma análise de consistência dos dados e para aquelas estações que apresentaram falhas na série, foi necessário o preenchimento das falhas existentes, haja vista que a ausência de informações pode comprometer o cálculo do Índice de Anomalia de Chuvas.

O preenchimento das falhas para a viabilização dos cálculos desenvolvidos foi realizado utilizando-se o Método do Vetor de Ponderação Regional, a qual se caracteriza, na visão de Bertoni e Tucci (2013), como uma maneira mais sintética e comumente utilizada em séries anuais e mensais de precipitações, cujo intuito concentra-se no alcance da homogeneização dos dados avaliados. O equacionamento do método encontra-se na equação 1 abaixo:

$$
P x=\frac{N x}{n} \sum_{i}^{n} \cdot\left(\frac{P i}{N i}\right)
$$

onde, $\mathrm{Px}=$ precipitação a ser estimada para o ponto $\mathrm{x} ; \mathrm{Pi}=$ precipitação correspondente ao mês ou ano observados nas estações vizinhas; $\mathrm{Ni}$ = são as respectivas precipitações médias nas estações vizinhas; $\mathrm{Nx}=$ precipitação média mensal ou anual do posto $\mathrm{x} ; \mathrm{n}=\mathrm{n}^{\mathrm{o}}$ de postos vizinhos.

A identificação das falhas foi realizada por observação dos meses que possuíam valores menores ou iguais a $1 \mathrm{~mm}$ ou sem valor. Foram revistos todos os valores com essa condição, inclusive os dados consistidos.

\section{3 Índice de Anomalia de Chuva (IAC)}

Na determinação do Índice de Anomalia de Chuva (IAC), foi utilizada a metodologia sugerida por Rooy (1965), a fim da obtenção das anomalias positivas e negativas, seguindo as equações 2 e 3 : 


$$
\begin{array}{ll}
I A C_{\text {positivo }}=-3\left[\frac{(N-\bar{N})}{(\bar{X}-\bar{N})}\right] & \text { Equação 2 } \\
I A C_{\text {negativo }}=3\left[\frac{(N-\bar{N})}{(\bar{X}-\bar{N})}\right] & \text { Equação 3 }
\end{array}
$$

em que, $\mathrm{N}=$ precipitação observada do ano em que será gerado o IAC $(\mathrm{mm}) ; \mathrm{N}^{-}=$precipitação média anual da série histórica $(\mathrm{mm}) ; \mathrm{X}^{-}=$média das dez maiores precipitações anuais da série histórica $(\mathrm{mm})$.

Uma vez determinados os valores do IAC, realizou-se a classificação conforme a metodologia de Araújo et al. (2009), descrita na Tabela 3 a seguir:

Tabela 3. Classificação do Índice de Anomalia de Chuva (IAC).

\begin{tabular}{cc}
\hline Índice de Anomalia de Chuva (IAC) & Classificação da Precipitação \\
\hline Maior que 4 & Extremamente Chuvoso \\
Entre 2 e 4 & Muito Chuvoso \\
Entre 0 e 2 & Chuvoso \\
0 & Nem Chuvoso Nem Seco \\
Entre 0 e -2 & Seco \\
Entre -2 e -4 & Muito Seco \\
Menor que -4 & Extremamente Seco \\
\hline
\end{tabular}

Fonte: Araújo (2009).

\section{Resultados e Discussão}

\subsection{Caracterização da precipitação pluviométrica}

Conforme Tabela 4, onde são apresentados os valores médios mensais e totais anuais para cada estação, pode-se observar que o período de maior precipitação na região em estudo, se concentra entre os meses de novembro a março, cujos totais precipitados variaram entre 557,9 mm (estação 2040000) à 1212,6 mm (estação 2040020), correspondendo respectivamente, $57,18 \%$ e $60,33 \%$ do total acumulado no período. O mês de dezembro apresentou os maiores volumes precipitados em 7 das 10 estações, com amplitude de variação entre 203,32 mm (estação 2041000) a 338,52 mm (estação 2041017). Nas estações 2040022, 2040005 e 2040000 os maiores totais precipitados ocorreram no mês de novembro, cujos valores foram respectivamente de 169,7 mm, 262,5 mm e 173,4 mm. Os meses de julho (estações 2041016, 2041001, 2040020, 2041021, 2041015 e 2041017) e agosto (estações 2040022, 2041000, 2040005 e 2040000) foram os que apresentaram os menores totais precipitados. Para o mês de julho os valores de precipitação variaram entre 25,96 mm (2,4\% do total anual ocorrido na estação 2041000) e 61,85 mm (4,40\% do total anual ocorrido na estação 2040022). Já para o mês de agosto, o menor valor precipitado ocorreu na estação 2041017, correspondendo a 12,0 $\mathrm{mm}(0,78 \%$ do total anual) e o maior foi registrado na estação 2040020 com 82,7 mm (4,11\% do total anual). A precipitação total anual variou entre 975,6 mm (estação 2040000) e 2010,1 mm (estação 2040020), apresentando como precipitação média pra a região em estudo igual a 1466,4 mm. De maneira geral, à medida que aumenta a altitude da estação, os totais precipitados são maiores. A estação 2040022 que apresenta a menor altitude, $3 \mathrm{~m}$, apresentou o menor total anual, cujo valor foi de 1183,8 mm. Já a estação 2040020 que possui a maior altitude, $980 \mathrm{~m}$, apesentou o maior total anual, $2010,0 \mathrm{~mm}$. 
Tabela 4. Estações pluviométricas, precipitação média mensal (mm) e total anual (mm) das estações adotadas.

\begin{tabular}{|c|c|c|c|c|c|c|c|c|c|c|}
\hline \multirow[b]{2}{*}{ Mês } & \multicolumn{10}{|c|}{ Estações pluviométricas } \\
\hline & 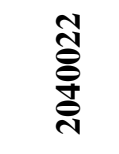 & 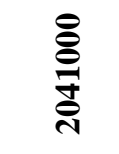 & $\begin{array}{l}\stackrel{\sigma}{0} \\
\stackrel{\vec{\theta}}{\vec{d}}\end{array}$ & 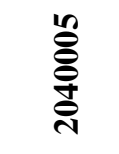 & $\begin{array}{l}\overrightarrow{8} \\
\stackrel{\vec{\Xi}}{\vec{\jmath}}\end{array}$ & 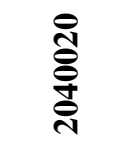 & 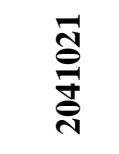 & $\frac{n}{\stackrel{n}{0}}$ & $\begin{array}{l}\text { } \\
\stackrel{8}{8} \\
\stackrel{8}{8}\end{array}$ & $\frac{\vec{\theta}}{\vec{\theta}}$ \\
\hline Janeiro & 106,1 & 132,4 & 224,5 & 161,7 & 226,0 & 230,1 & 231,2 & 193,4 & 94,4 & 264,0 \\
\hline Fevereiro & 75,6 & 85,0 & 143,2 & 100,4 & 144,9 & 161,5 & 141,7 & 123,8 & 52,7 & 139,2 \\
\hline Março & 141,0 & 149,9 & 239,7 & 180,8 & 215,4 & 236,6 & 224,7 & 190,1 & 87,7 & 180,7 \\
\hline Abril & 93,0 & 85,4 & 109,9 & 144,6 & 104,5 & 152,4 & 125,4 & 117,9 & 76,5 & 98,8 \\
\hline Maio & 90,8 & 40,4 & 67,3 & 96,6 & 48,3 & 109,8 & 61,6 & 58,5 & 64,5 & 45,1 \\
\hline Junho & 67,8 & 29,0 & 28,2 & 75,5 & 22,5 & 82,7 & 38,7 & 37,9 & 44,1 & 18,5 \\
\hline Julho & 67,9 & 27,6 & 24,4 & 80,5 & 15,0 & 86,7 & 31,4 & 27,5 & 42,4 & 12,0 \\
\hline Agosto & 52,1 & 26,0 & 31,0 & 61,8 & 29,8 & 88,7 & 39,0 & 33,2 & 38,2 & 18,7 \\
\hline Setembro & 61,8 & 46,9 & 70,1 & 106,2 & 62,5 & 107,4 & 72,8 & 64,6 & 59,6 & 53,6 \\
\hline Outubro & 93,1 & 87,0 & 129,0 & 138,9 & 101,2 & 169,8 & 121,1 & 102,8 & 92,4 & 117,0 \\
\hline Novembro & 169,7 & 169,2 & 268,1 & 262,5 & 240,4 & 281,3 & 263,0 & 234,1 & 173,4 & 249,4 \\
\hline Dezembro & 165,0 & 203,3 & 307,6 & 218,7 & 294,9 & 303,0 & 309,0 & 256,9 & 149,7 & 338,5 \\
\hline Total & 1183,8 & 1082,1 & 1643,0 & 1628,2 & 1505,4 & 2010,1 & 1659,6 & 1440,8 & 975,6 & 1535,6 \\
\hline
\end{tabular}

Fonte: Autores (2021).

Na Figura 2 é possível visualizar o comportamento da precipitação média mensal dos 30 anos avaliados na região estudada. Observa-se que os meses de maior precipitação são respectivamente, dezembro (254,7 mm) novembro (231,1 mm), janeiro (186,4 mm) e março $(184,7 \mathrm{~mm})$. Os meses de abril a setembro são os que apresentaram os menores totais precipitados (25,7\% do total anual de 1466,4 mm), cuja amplitude de variação foi de 41,5 mm (julho) e 110,8 mm (abril). Os meses de fevereiro, abril, maio, junho, julho e setembro, apresentaram os totais precipitados inferiores à média da região, cujo valor obtido foi de $122,2 \mathrm{~mm}$. 
Figura 2. Comportamento da precipitação média mensal (mm) na área de estudo.

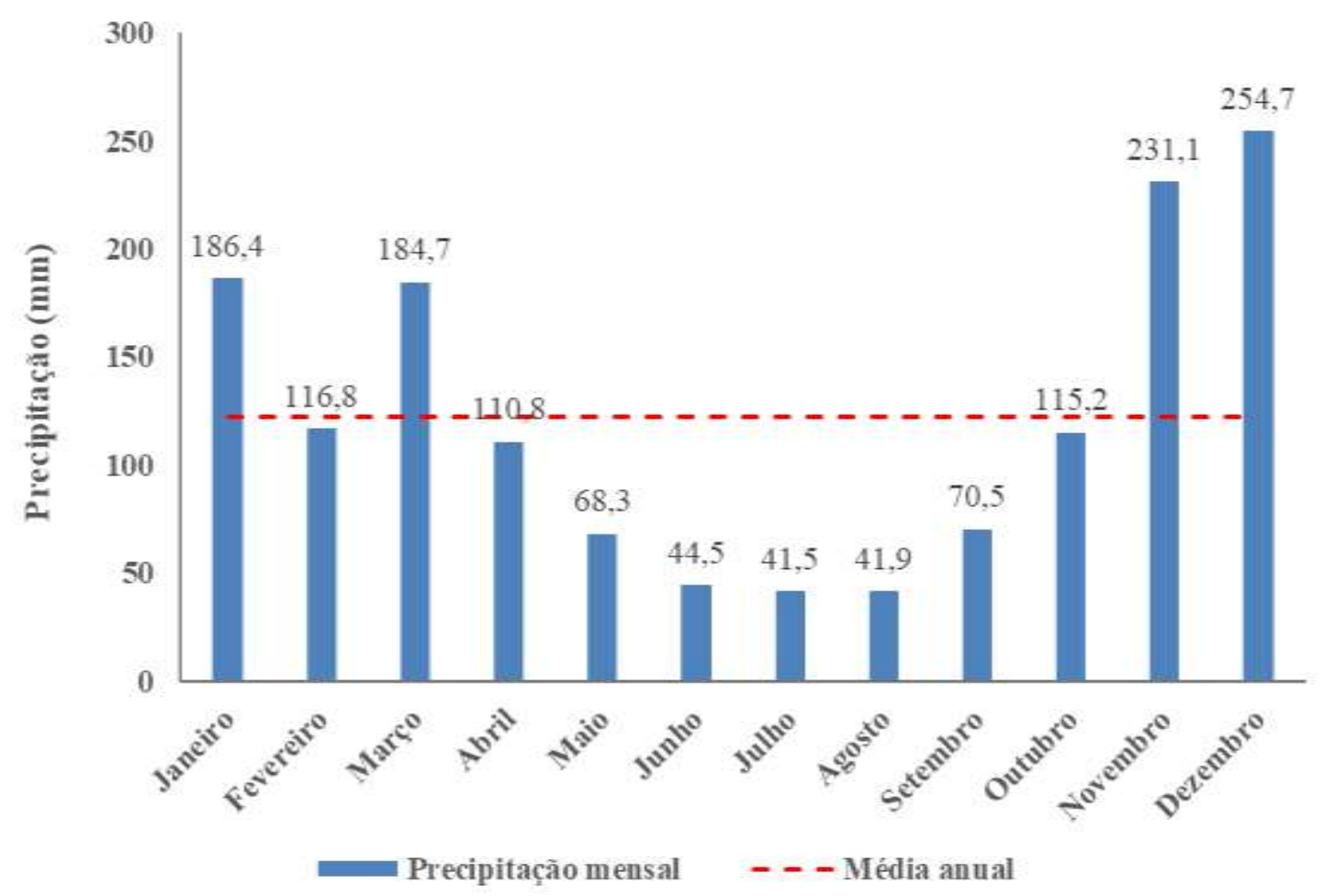

Fonte: Autores (2021).

\subsection{Análise do Índice de Anomalia de Chuvas}

Conforme apresentado na Figura 3, a estação 2040005 apresentou 15 anos com anomalia positiva (50\% dos anos), cuja classificação do IAC variou entre chuvoso e extremamente chuvoso, porém, estes anos são precedidos de anomalias negativas, variando entre anos seco (IAC entre 0 e -2) a extremamente seco (IAC menor que -4). Entre os anos de 2009 e 2019 houve uma sequência de anos com anomalia negativa cujo ápice ocorreu no ano de 2014 (classificado como extremamente seco), ano em que foram observados problemas relacionados a disponibilidade hídrica em várias regiões do país. Esta sequência de baixos volumes precipitados dificulta o aumento da disponibilidade hídrica na região. Uma das possíveis explicações é a sequência de anos influenciados pela La Niña classificada como moderada ocorrida nos anos 1999 - 2000, 2007 - 2008 e 2010 - 2011, contribuindo para a redução do volume precipitado. Além disso, segundo Coelho et al. (2016b), a ocorrência do déficit de precipitação que proporcionou a seca sobre a região sudeste do Brasil, pode ser explicada pelo desencadeamento de condições de atividade convectiva anômala ocorrida na região tropical ao norte da Austrália, desencadeando uma sequência de processos conectados a região tropical e extra-tropical do oceano Pacífico, atingindo o oceano Atlântico e a região sudeste do Brasil. Estabelecendo um sistema anômalo de alta pressão sobre o oceano Atlântico, que desfavoreceu a formação de eventos da Zona de Convergência do Atlântico Sul (ZACAS), um dos principais mecanismos de formação de chuvas sobre a região sudeste. Coelho et al. (2016a) trabalhando com o índice padronizado de precipitação na região sudeste, mais precisamente no estado de São Paulo, identificou para o período de dezembro de 2013 a março de 2014 e de dezembro de 2014 a março de 201, valores deste índice iguais a -3,66 e -1,47, respectivamente, sendo classificados, segundo a agência Americana (NOAA), como um evento excepcionalmente seco em 2013/2014 e muito seco em 2014/2015, corroborando com os resultados encontrados no presente estuado. Já o ano de 2020 foi classificado como extremamente 
chuvoso. É possível observar dois períodos com sequências de anos mais secos, 1998 a 2020, onde se destaca o ano de 2001 extremamente seco e 2010 a 2017 (La Niña moderada 2017 - 2018), com exceção do ano de 2013 (IAC igual a 1,9).

De maneira semelhante ocorreu na estação 2040020, onde 15 anos apresentaram anomalia positiva, cujos valores do IAC variaram entre 0,1 (chuvoso no ano de 2006) e 6,5 (extremamente chuvoso no ano de 1996). Nos últimos anos, 2008 a 2019, também foram observadas uma sequência de anos com anomalia negativa, caracterizando-se por anos com baixos totais precipitados, cujas classificações variaram entre seco e extremamente seco. A intensidade dos anos com anomalia negativa é maior que a estação 2040005. Fica evidente uma possível alteração no padrão de chuvas a partir do ano de 1999, onde em 13 dos 22 anos avaliados ocorreu a prevalência de anos com anomalia negativa (Figura 3).

Figura 3. Índice de Anomalia de Chuva para as estações 2040005 (Iconha - Montante) e 2040020 (Vila Nova Maravilha).

Estaçao 2040005

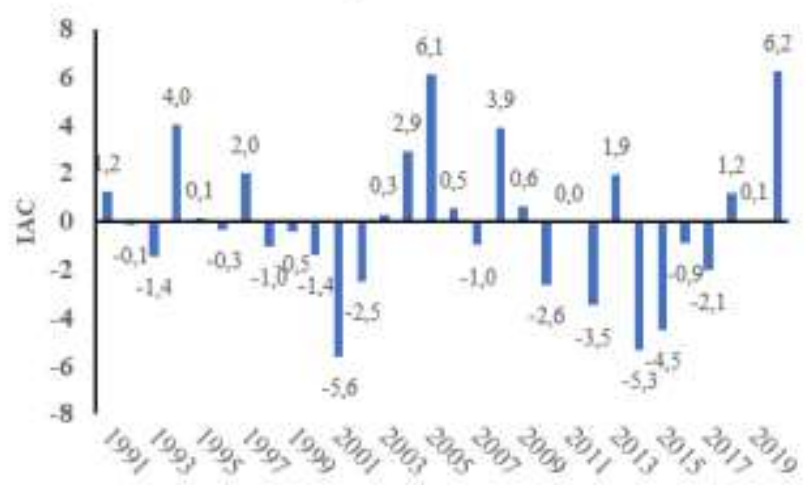

Estação 2040020

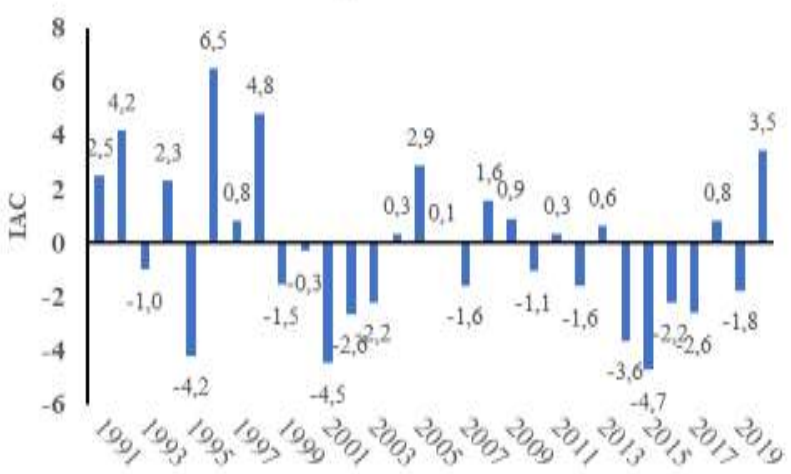

Fonte: Autores (2021).

A estação 2040022 diferentemente das estações anteriores, apresenta sequência de anos com anomalia positiva mais expressiva, principalmente entre os anos de 2004 (IAC igual a 4 classificados como extremamente chuvoso) a 2013 (IAC igual a 4,8 classificados como extremamente chuvoso), com exceção dos anos 2006 e 2007 (anomalia negativa classificados respectivamente, seco e muito seco). Além de apresentar mais anos com anomalia positiva, apenas 1 dos anos avaliados foi classificado como extremamente seco, os demais foram no máximo classificado como muito seco. O ano de 2020 foi classificado como muito chuvoso. Entre os anos de 1991 e 2003, ocorreram mais anos secos do que chuvosos, a partir de então, os valores de IAC foram mais elevados, caracterizando-se como anos mais chuvosos, muito chuvosos e extremamente chuvosos (Figura 4).

Semelhantemente à estação 2040022, a estação 2041000 apresentou 17 anos cujas anomalias foram positivas, com classificações variando entre chuvoso (anos de 1992, 1993, 1995, 2002, 2003, 2004, 2006, 2011, 2012 e 2018), muito chuvoso (para os anos de 1991, 1994, 2008, 2013 e 2020) e extremamente chuvoso no ano de 2005. Apresentou uma sequência de anos com anomalia negativa entre 1996 e 2001, com o menor valor de IAC igual a -3,1 no ano de 2001, sendo classificado como muito seco. Entre os anos de 2017 e 2020, apresenta uma alternância entre anomalia negativa e positiva, com valores de IAC iguais a -2,6 (muito seco) para o ano de 2017, 1,3 (chuvoso) para o ano de 2018, -3,3 (muito seco) para o ano de 2019 e 2,6 (muito chuvoso) para o ano de 2020 (Figura 4). 
Figura 4. Índice de Anomalia de Chuva para as estações 2040022 (Ponta da Fruta) e 2041000 (Atílio Vivácqua).

Estação 2040022

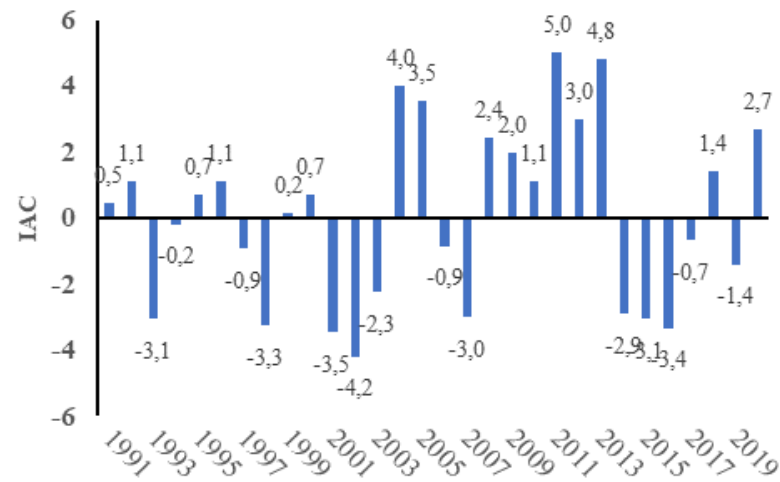

Estação 2041000

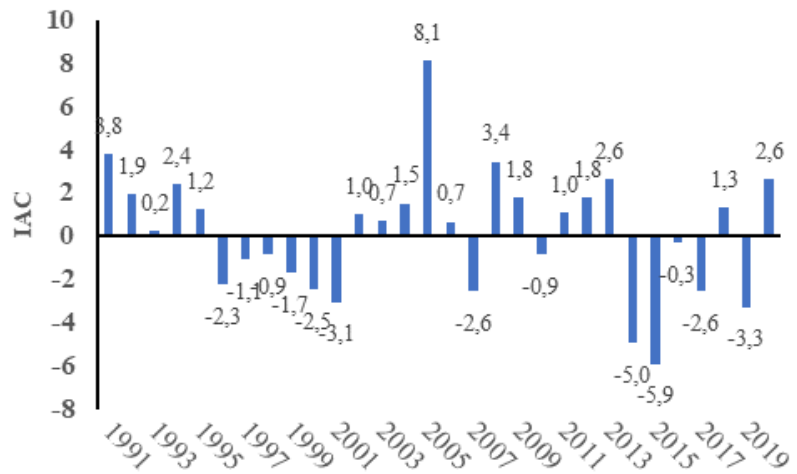

Fonte: Autores (2021).

Conforme Figura 5, a estação 2041001 apresentou entre os anos de 1991 e 1998 uma sequência de anos com anomalia negativa, porém, com baixa intensidade, visto que os valores do IAC variaram entre -0,2 (seco - 1995) e -2,1 (muito seco - ano de 1993). Dos 15 aos que apresentaram anomalia positiva, 10 foram classificados com chuvosos, 1 como muito chuvoso e 4 como extremamente chuvosos (2004, 2005, 2008 e 2009). Entre os anos de 2014 e 2017, ocorreu uma sequência de anos com anomalia negativa, cujas classificações variaram entre extremamente seco (2014, 2015 e 2017), seco em 2016 e muito seco em 2019. Percebe-se novamente como nas demais estações, que nos últimos anos tem ocorrido anos com baixos totais precipitados. Este fato pode ter relação com as alterações climáticas que vem ocorrendo nos últimos anos, conforme observado por Marrafon et al. (2020) estudando o comportamento da precipitação na América do Sul, trabalhando com dados da análise do Climate Predicition Center (CPC-NOAA), no período de 1979 a 2019. Constataram que em grande parte do Brasil, na banda que se estende da Amazônia em direção à região sudeste do país (Zona de Convergência do Atlântico Sul - ZCAS), há tendência de redução do volume sazonal e anual da precipitação e da sequência de dias úmidos e aumento da sequência de dias secos, corroborando para os resultados alcançados no presente trabalho. Silva et al. (2020) analisando as projeções resultantes de nove modelos participantes do Coordinated Regional Climate Downscaling Experiment (CORDEX), considerando os cenários representative concentration pathways (RCP) 4.5 e RCP8.5 para o século XXI, também observaram tendência de redução no total precipitado na região Hidrográfica do Atlântico Sudeste, justamente onde se localiza a área estudada no presente trabalho. Fora identificadas anomalias negativas no sudeste e principalmente no sul do Brasil, conforme também observado pelo autore Da Rocha (2014), nas regiões do Atlântico Sudeste (RCP8.5, de 2006 a 2035, sinalizando reduções na precipitação. Fica evidente 3 períodos distintos, entre os anos de 1991 e 2003 prevaleceram uma sequência de anos secos, seguidos de um período de anos extremamente chuvosos (2004, 2005 e 2008 e 2009), anos chuvosos (2006 e 2007 ) e outra sequência de anos secos (2016), muito secos (2012 e 2019) e extremamente seco (2014 e 2015).

Na Figura 5, percebe-se que a estação 2041015 apresentou 14 anos com anomalia positiva e uma sequência de mais anos com anomalia positiva e do que negativa. Entre os anos de 2003 e 2013, com exceção dos anos de 2007 (IAC igual a -3,0 muito seco) e 2012 (IAC igual a -3,7 muito seco), apresentaram anomalia positiva, cujos valores do IAC e suas classificações foram de 0,5 para o ano de 2003 (chuvoso), 3,8 para 2004 (muito chuvoso), 4,8 para 2005 (extremamente chuvoso), 1,4 para 2006 (chuvoso), 3,5 para 2008, 2,4 para 2009, 2,1 para 2011 e 2,6 para 2013 sendo classificados como muito chuvoso. Entre 2017 (-2,7 classificado como muito seco) e 2020 (3,1 classificado como muito chuvoso), houve alternância entre anomalia positiva (2018 e 2020) e negativa (2017 e 2019). 
Figura 5. Índice de Anomalia de Chuva para as estações 2041001 (Guaçuí) e 2041015 (Fazenda Monte Alegre).

Estação 2041001

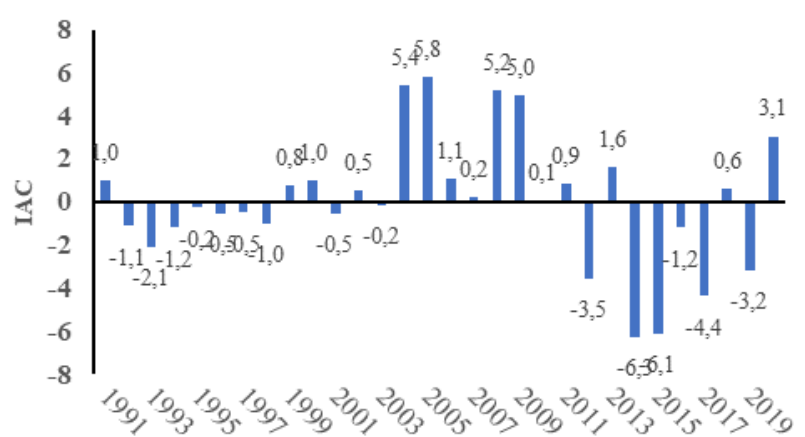

Estação 2041015

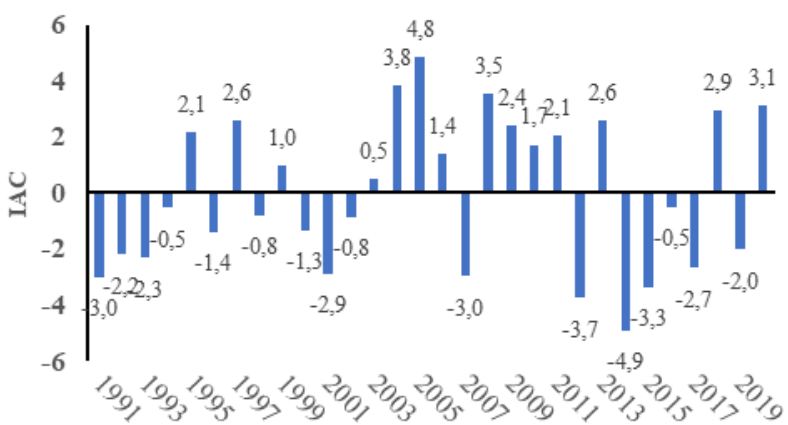

Fonte: Autores (2021).

Na estação 2041016 foram identificados 17 anos com anomalia negativa, cujas classificações variaram entre seco (anos de 1991, 1992, 1995, 1996, 1998, 2000, 2003, 2007, 2012 e 2020), muito seco (anos de 1993, 1999, 2014, 2015 e 2019) e extremamente seco para os anos de 2001 e 2017. Apenas os anos de 2004 e 2005 foram classificados como extremamente chuvosos, 2008, 2009, 2013 e 2018 como anos muito chuvosos, os demais anos foram classificados como chuvosos. Entre os anos de 2014 e 2020, apenas os anos de 2016 (chuvoso) e 2018 (muito chuvoso) apresentaram anomalia positiva (figura 6).

Na estação 2041017 ocorreram 17 anos com anomalia positiva, extremamente chuvoso para o ano de 1992, muito chuvoso para os anos de 1991, 1997, 2004, 2005, 2008, 2009, 2011 e 2020, com valores de IAC variando entre 0,8 a 4,2. Entre os anos de 2015 e 2020, ocorreu uma alternância entre anomalias negativas e positivas, variando de extremamente seco em 2015 a muito chuvoso em 2020 (Figura 6).

Figura 6. Índice de Anomalia de Chuva para as estações 2041016 (Ibitirama) e 2041017 (Santa Cruz - Caparaó).

\section{Estação 2041016}

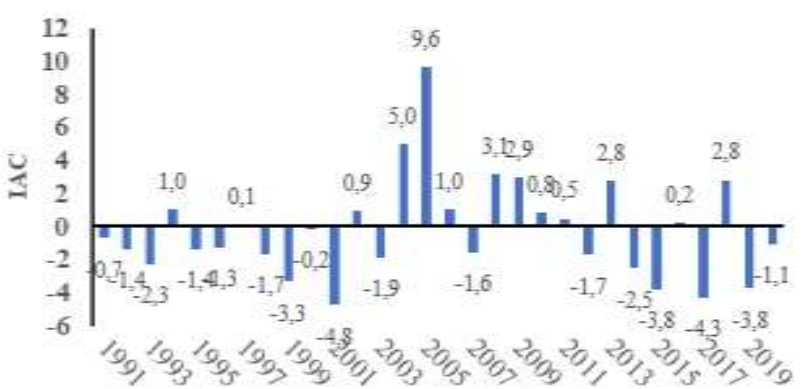

Estação 2041017

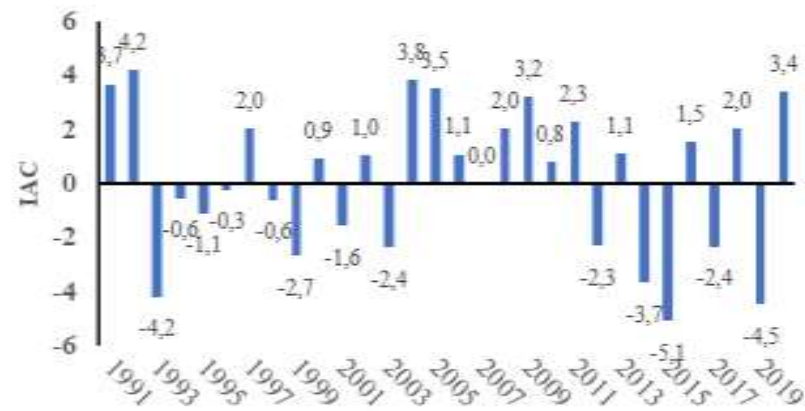

Fonte: Autores (2021).

A estação 2041021 apresentou 15 anos com anomalia positiva, 6 anos classificados como chuvosos, 8 anos como muito chuvosos e 1 ano como extremamente chuvoso (2005). Em contra partida, os anos com anomalia negativa apresentaramse com maior severidade entre os anos de 2012 e 2019, com a maior intensidade no ano de 2015 (IAC de -5,7 sendo classificado como um ano extremamente seco). Com exceção dos anos de 2013, 2018 e 2020, a partir do ano de 2012 houve 
uma sequência de anos com anomalia negativa, com classificações variando entre seco (2014 e 2016), muito seco (2012 e 2019) e extremamente seco para os anos de 2015 e 2017 (Figura 7).

Já a estação 2040000 é a que apresenta a maior severidade com relação ao baixos volumes precipitados, pois apenas 11 dos 30 anos estudados apresenta anomalia positiva, sendo 4 anos classificados como extremamente chuvoso (1992, 2004, 2005 e 2008), 2 anos classificados com muito chuvosos (1994 e 2013) e 5 anos chuvosos (1991, 1997, 2003, 2009 e 2012). A partir do ano de 2014 (extremamente seco) até o ano de 2020, apresenta uma sequência de anomalias negativas, atingindo o valor do IAC no ano de 2020 igual a -2,1 (muito seco). Muito possivelmente a região desta estação esteja com problemas relacionados à disponibilidade hídrica, frente ao longo período com baixos volumes precipitados (Figura 7).

Figura 7. Índice de Anomalia de Chuva para as estações 2041021 (Burarama) e 2040000 (Domingos Martins (DNOS)).

Estaç̄o 2041021

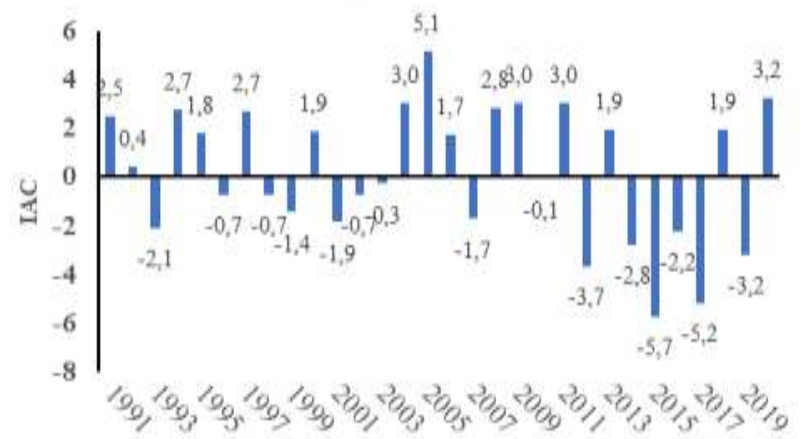

Estação 2040000

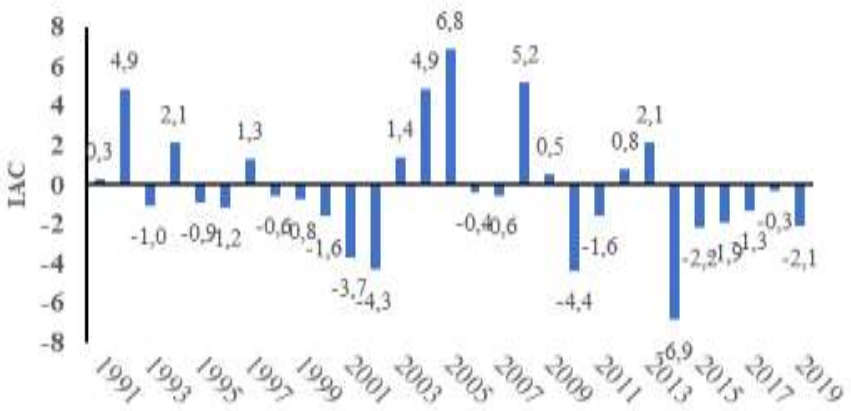

Fonte: Autores (2021).

Destaca-se que no ano de 2015 todas as estações apresentaram o IAC classificado como extremamente seco, provavelmente, devido à sequência de anos com anomalia de chuvas negativos, reduzindo a disponibilidade hídrica da região, ressalta-se que no referido ano ocorreu a pior crise hídrica da história do estado, conforme reportado por diversos autores (Marengo et al. 2015; Pantaleão et al. 2020; Espírito Santo 2015). Uma das hipóteses plausíveis, segundo Marengo et al. (2014), está associada ao desmatamento da região Amazônica, vista a forte influência da Zona de Convergência do Atlântico Sul (ZCAS) na precipitação de grande parte do Brasil, inclusive na região sudeste. Segundo os autores, dados numéricos sobre esse desmatamento indicam que ele pode gerar ressecamento e aumento da temperatura, afetando o clima e hidrologia na região e consequentemente, enfraquecimento da ZACAS.

Na região do Rio Itapemirim (estações 2040000, 2041000, 2041015, 2041016, 2041017 e 2041021) nas regiões próximas a cabeceira, possui presença significativa de cultivos agrícolas, além de áreas com mata nativa, enquanto na porção média, ocorre o predomínio de pastagens e mais próximo da foz, cultivos agrícolas e áreas urbanas (Espírito Santo, 2018). Frente a isso, anos seguidos de anomalias negativas conforme encontrados nas estações descritas acima, podem ocasionar conflitos pelo uso da água entre a agricultura e a dessendentação de animais e abastecimento humano. Estas constatações, proporcionam informações importantes para que os órgãos gestores dos recursos hídricos possam gerir de maneira eficiente este recurso tão importante.

Embora as estações 2040005, 2040020, 2041015, 2041017 e 2041016 sejam classificadas com zonas naturais chuvosas (Tabela 1), vem sofrendo longos períodos com anomalias negativas, ou seja, com totais precipitados abaixo da média, principalmente, as estações 2040005, 2040020 e 2040016, cujos últimos 10 anos tem apresentado períodos críticos quanto a disponibilidade hídrica. Já as estações 2040022 e 2041001, cuja classificação segundo as zonas naturais é transição 
entre chuvosa/seca (Tabela 1), de acordo com a análise do IAC, segue o esperado segundo as zonas naturais, com alternância entre períodos de anomalias positivas e negativas. Com relação às estações 2041000, 2041021 e 2040000, consideradas zonas naturais secas (Tabela 1), com exceção da estação 2041021 (predominância de anomalia positiva), as demais apresentam a predominância de anomalias negativas, corroborando com a classificação das zonas naturais.

Na Figura 8 é apresentado o índice IAC médio para a região estudada. Percebe-se a predominância de vários anos com anomalias negativas (anos mais secos) em sequência, como ocorrido entre os anos 1998 a 2003 (5 anos secos e 1 ano extremamente seco) e 2014 a 2017 ( 2 anos extremamente seco, 2 anos muito seco e 1 ano seco). Além disso, aqueles anos que apresentaram anomalia positiva, 7 anos foram classificados com chuvosos, 5 como muito chuvosos e 1 como extremamente chuvoso. Esta constatação, predominância de anos com anomalia negativa, pode proporcionar prejuízos na agricultura dentre outros fatores, períodos secos podem culminar em grandes dificuldades devido à escassez hídrica, proporcionando períodos de seca, prejudicando sobremaneira a agricultura pela falta de chuvas, como outras interações danosas ao meio (Diniz, et al. 2020).

Entre os anos de 1991 e 2003, prevaleceram anos com anomalia negativa, ou seja, anos mais secos que chuvosos. Neste período de 13 anos, 8 deles, apresentou-se como seco (1993, 1995, 1996, 1998, 1999, 2000, 2002 e 2003 ) e 1 como extremamente seco (2001). O período pós 2003 é evidentemente mais úmido que o anterior (anos seguidos com altos valores de IAC), caracterizando-se como um possível "ponto de inflexão", a partir do qual ocorre uma possível modificação no padrão de chuva local. A partir do ano de 2004, ocorreu uma alternância entre anos chuvosos e secos, onde a intensidade dos anos chuvosos (valores de IAC) foi maior do que os anos secos, com exceção dos anos de 2014 e 2015, classificados como extremamente secos. Este "ponto de inflexão" também foi observado por (Costa et al. 2017, Araújo et al. 2007, Araújo et al. 2009 e Da Silva, 2009) em seus trabalhos com IAC.

Figura 8. IAC médio anual na área de estudo entre os anos de 1991 e 2020.

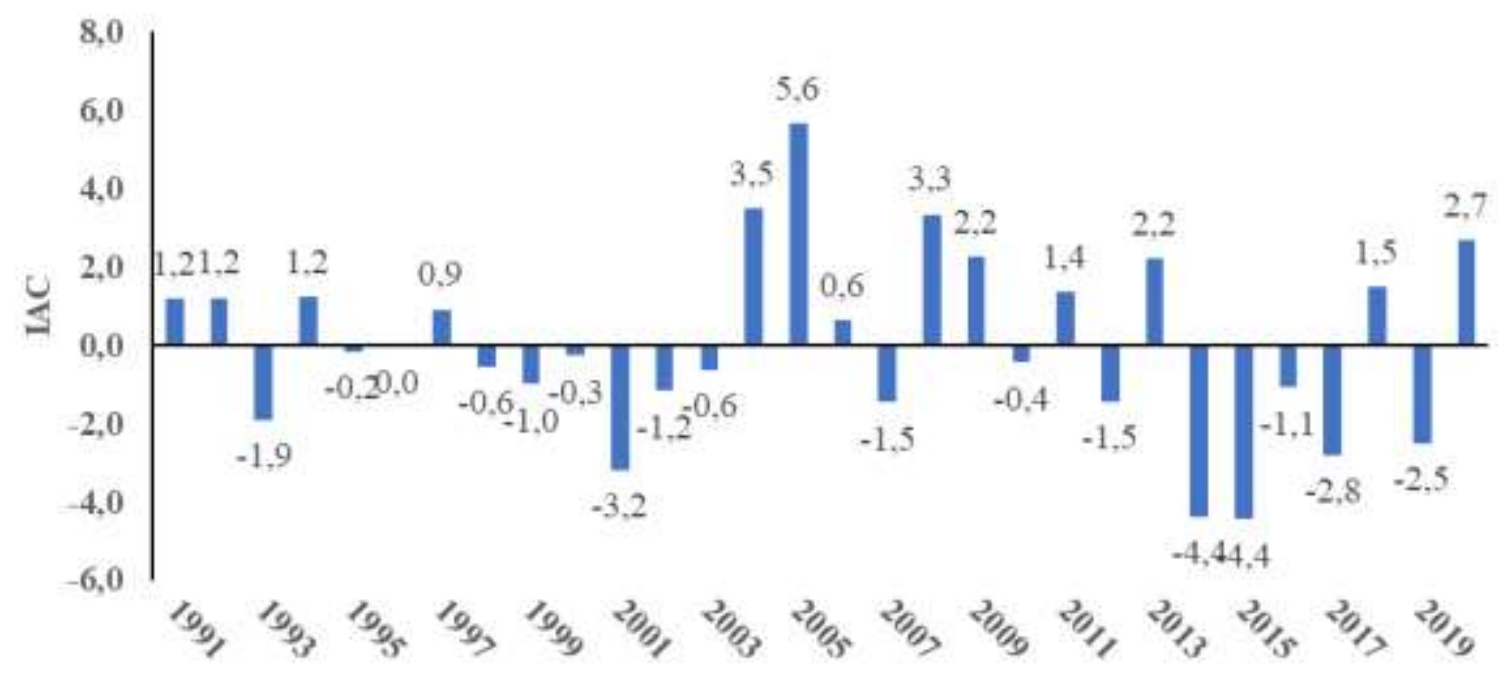

Fonte: Autores (2021).

Alguns autores tem utilizado o índice IAC para caracterizar os precipitação em uma região de interesse. Tavares et al. (2021) trabalhando com o IAC para o município de Juiz de Fora na região da Zona da Mata trabalhando com séries de precipitações entre 1910 e 2017, também observou anomalias positivas e negativas ao logo da série. Destaca-se o ano de 2015, no qual também foram observados totais precipitados abaixo da média, sendo classificado com muito seco. Noronha et al. (2015), analisando a intensidade da anomalia temporal do regime de chuva, aplicou o índice IAC em seus estudos na 
microbacia de Santa Maria/Cambiocó, na região noroeste do estado do Rio de Janeiro. Constataram classificações variando desde extremamente seco a extremamente chuvoso. Não conseguiram constatar alterações no regime pluviométrico ao longo da série observada que pudessem influenciar a seca meteorológica. Nery et al. (2020), analisaram o índice IAC para a região do estado do Paraná a fim de analisar as anomalias no regime pluviométrico da região. Observaram que, contrariamente ao encontrado no presente trabalho (fato explicado devido às diferenças climáticas das regiões), prevaleceram as anomalias positivas, inclusive para o ano de 2015. Concluíram que a utilização do índice IAC mostrou-se ser uma "ferramenta" útil para análise de períodos secos e chuvosos.

\section{Conclusão}

A análise do IAC possibilitou analisar o comportamento da precipitação pluviométrica, sendo considerado um indicador climático capaz avaliar períodos secos e chuvosos. Foram identificados em todas as estações pluviométricas períodos com anomalias positivas (chuvoso, muito chuvoso e extremamente chuvoso) e anomalias negativas (seco, muito seco e extremamente seco). Vale destacar as estações 2040020, 2041016 e 2040000 que apresentaram anomalias negativas intensas (extremamente seco) nos últimos anos. Em contra partida as estações 204022, 20410155, 2041017 e 2041021 apresentam uma condição hídrica mais favorável, de maneira geral, ocorreu alternância entre anos com anomalias positivas e negativas. Foi possível observar um possível "ponto de inflexão" no ano de 2003, a partir do qual ocorre uma mudança no padrão de chuvas na região, quando se analise o IAC médio.

A precipitação média anual da região foi de 1466,4 mm, com amplitude de variação de 975,6 mm (estação 2040000, classificada como zona natural seca - sudeste da ottobacia do Rio Itapemirim) a 2010,1 mm (estação 2040020, cuja zona natural é chuvosa - sudoeste da ottobacia Rio Benevente), valores estes, condizentes com a classificação das zonas naturais do Estado do Espírito Santo. Destaca-se a estação 2041021 (região central da ottobacia do Rio Itapemirim) que apesar de localizada na zona natural seca, apresentou o segundo maior total precipitado na região em estudo (1659,6 mm). Os meses de fevereiro, abril, maio, junho, julho e setembro, apresentaram os totais precipitados inferiores à média da região, cujo valor obtido foi de $122,2 \mathrm{~mm}$.

\section{Referências}

Alvares, C. A., Stape, J. L., Sentelhas, P. C., de Moraes, G., José Leonardo, \& Sparovek. Köppen's climate classification map for Brazil (2013). Meteorologische Zeitschrift, 22(6), 711-728.

Araújo, L. E., Da Silva, D. F., Moraes Neto, J. M., \& Sousa, F. A. S. de. (2007). Análise da Variabilidade Espaço-Temporal da precipitação na Bacia do rio Paraíba usando IAC. Revista Brasileira de Meteorologia, 23, 162-169. https://doi.org/10.51359/2238-6211.2007.228680

Araújo, L. E., Moraes Neto, J. M., \& Sousa F. A. S. (2009). Análise climática da bacia do rio Paraíba - Índice de Anomalia de Chuva (IAC). Revista de Engenharia Ambiental, 6(3), 508-523.

Araújo, L. E., Neto, J. M. M., \& Sousa, F. A. S. (2009). Análise climática da bacia do Rio Paraíba - Índice de Anomalia de Chuva (IAC). Engenharia Ambiental - Unipinhal, 6, 508-523.

Coelho, C. A. S., Cardoso D. H. F., \& Firpo M. A. F. (2016 ${ }^{\mathrm{a}}$. Precipitation diagnostics of an exceptionally dry event. in: São Paulo, Brazil. Theor Appl Climatol. 125(3): 769-784. 10.1007/s00704-015-1540-9.

Coelho, C. A. S., de Oliveira, C. P., Ambrizzi, T., Reboita, M. S., Carpenedo, C. B., Campos, J. L. P. S., Tomaziello, A. C. N., Pampuch, L. A., Custódio, M. S., Dutra, L. M. M., Da Rocha, R. P., \& Rehbein, A. (2016b). The 2014 southeast Brazil Austral summer drought: regional scale mechanisms and teleconnections. Climate Dynamics. 46(11): 3737-3752. 10.1007/s00382-015-2800-1.

Costa, J. A., \& Silva, D. F. (2017). Distribuição espaço-temporal do Índice de anomalia de chuva para o Estado do Ceará. Revista Brasileira de Geografia Física, 10(4), 1002-1013.

Da Silva, D. F. (2009). Análise de aspectos climatológicos, ambientais, agroeconômicos e de seus efeitos sobre a Bacia hidrográfica do rio Mundaú (AL e $P E$ ). Tese (Doutorado), Campina Grande UFCG. 
Diniz, R. R. S., Alencar, M. L. S., Medeiros, S. A., Guerra, H. O. C., \& Sales, J. C. R. (2020). Índice de anomalia de chuvas da Microrregião do Cariri Ocidental Paraibano. Revista Brasileira de Geografia Física, 13(6), 2628-2640.

Espírito Santo. (2018). Agência Estadual de Recursos Hídricos - AGERH. Diagnóstico e Prognóstico das Condições de Uso da Água na Bacia Hidrográfica do Rio Itapemirim: Relatório Etapa A - Diagnóstico e Prognóstico. Bacia Hidrográfica do Itapemirim, Espírito Santo, 201/. 583 p.

Espírito Santo (2015). Diário Oficial. Cenário de Alerta no ES devido a Pior Crise da História. Resoluções AGERH 005 e 006/2015. Vitória/ES, Terça-feira, 06 de outubro de 2015. <http://dio.es.gov.br/>

Silva, G. K., Silveira, C. S., Silva, M. V. M., Júnior, A. D. M., Filho, F. A. S., \& Guimarães, S. O. G. (2020) Análise de projeções das mudanças climáticas sobre precipitação e temperatura nas regiões Hidrográficas brasileiras para o século XXI. Brazilian Journal of Environmental Sciences, 55, $420-436$.

Köppen, W., \& Geiger, R. (1928). Klimate der Erde. Gotha: Verlag Justus Perthes. Wall-map $150 \mathrm{~cm}$ x $200 \mathrm{~cm}$.

Labat, D. et al. (2004). Evidence for global runoff increase related to climate warming. Advances in Water Resources, 27(6), 631-642.

Li, Y. et al. (2016). Contributions of climate variability and human activities to runoff changes in the upper catchment of the red River Basin, China. Water (Switzerland), 8(9).

Lorenzon, A. S., Fraga, M. S., Moreira, A. R., Uliana, E. M., Silva, D. S., Ribeiro, C. A. A. S., \& Borges, A. C. (2015). Influência das características morfométricas da bacia hidrográfica do rio Benevente nas enchentes no município de Alfredo Chaves-ES. Revista Ambiente e Água, 10, 327-345, Taubaté SP. https://doi.org/10.4136/ambi-agua.1475.

Marrafon, V. H., \& Reboita, M. S. (2020). Características da precipitação na América do Sul reveladas através de índices climáticos. Revista Brasileira de Climatologia, 26, 663 - 676, http://dx.doi.org/10.5380/abclima.v26i0.72181

Maniçoba, R. M., Sobrinho, J. E., Guimarães, Í. T., Junior. E. G. C., Silva. T. T. F., \& Zonta, J. H. (2017). Índice de anomalias de chuva para diferentes mesorregiões do Estado do Rio Grande do Norte. Revista Brasileira de Geografia Física, 10, 1110-1119.

Marengo, J. A., \& Alves, L. M. (2015). Crise Hídrica em São Paulo em 2014: Seca e Desmatamento. GEOUSP Espaço e Tempo (Online), 19, 485-494. http://dx.doi.org/10.11606/issn.2179-0892.geousp.2015.100879.

Marengo, J. A., Nobre, C., A., Seluchi, M. E., Cuartas, A., Alves, L. M., Mendiondo, E. M., Obregón, G., \& Sampaio, G. (2015). A seca e a crise hídrica de 2014-2015 em São Paulo. Revista USP, (106), 31-44. https://doi.org/10.11606/issn.2316-9036.v0i106p31-44.

Noronha, G. C., Hora, M. A. G. M., \& Silva, L. P. (2016). Análise do Índice de Anomalia de Chuva para a Microbacia de Santa Maria/Cambiocó, RJ. Revista Brasileira de Meteorologia, 31, 74-81. http://dx.doi.org/10.1590/0102-778620140160.

Pantaleão F., E., Broseghini Loss, J., Barcellos, A., \& Da Silva, F. A. (2020). Crise hídrica na bacia hidrográfica do Rio Santa Maria do Doce - ES: Caracterização, Avanços E Desafios. Revista Ifes Ciência, 6(4), 114-131. https://doi.org/10.36524/ric.v6i4.745

Oliveira, T. A., Tavares, C. M. G., Sanches, F., \& Ferreira, C, C. M. (2020). Variabilidade pluviométrica no município de Juiz de fora - MG no período de 1910-2018: investigação a partir da técnica do box plot. Revista Brasileira de Climatologia, 26, 457-478.

Reis, M. H., Griebeler, N. P., Sarmento, P. H. L., Oliveira, L. F. C. de, \& Oliveira, J. M. de. (2005). Espacialização de dados de precipitação e avaliação de interpoladores para projetos de drenagem agrícola no estado de Goiás e Distrito Federal. In: Simpósio Brasileiro De Sensoriamento Remoto, 12, 2005, Goiânia. Anais..., Goiânia: INPE, p. 229-236.

Rooy, M. P. V. (1965). A rainfall anomaly index independent of time and space. Notos, 14, 43-48.

Silva, A. R. S, Santos, T. S., Queiroz, D. É., Gusmão, M. O., \& Silva, T. G.F. (2017). Variações no índice de anomalia de chuva no semiárido. Journal of Environmental Analysis and Progress. 2, 377-384. http://www.ead.codai.ufrpe.br/index.php/JEAP/article/view/1420/482483571.

Siqueira, B., \& Nery, J. T. (2017). Análise do Índice Padronizado de Precipitação para o Estado de São Paulo. Revista Brasileira de Geografia Física, 10, 1775-1783.

Tavares, C. M. G., Carvalho, P. M., Oliveira, T. A., Sanches, F., \& Ferreira, C. C. M. (2021). O uso do Índice de Anomalia de Chuva (IAC) em Juiz de Fora Minas Gerais. Revista Equador (UFPI), 10, 222 - 244

Nery, J. T., \& Siqueira, B. (2020). Índice de Anomalia de Chuva aplicado ao estudo das precipitações no estado do Paraná. Revista Brasileira de Climatologia. $27,772-788$.

Vilar, R. A., Correia, M. F., Nóbrega, R. S., Aragão, M. R. S., Barbieri, L. F. P., \& Filho, M. G. M. (2021). Avaliação dos impactos de secas severas no nordeste brasileiro na geração de energia elétrica através do modelo Newave: Projeção de energias afluentes e armazenadas. Revista brasileira de meteorologia, 35, 89-98, 2020, http://dx.doi.org/10.1590/0102-778635100. 